\title{
Pupils' Perceptions on the Adoption and Use of Toontastic 3D, a Digital Storytelling Application for Learning Speaking Skills
}

\author{
Ife Sam 1 , Harwati Hashim² \\ ${ }^{1}$ Sekolah Jenis Kebangsaan Cina Khiak Yew, Melaka, Malaysia \\ ${ }^{2}$ Faculty of Education, Universiti Kebangsaan Malaysia, Bangi, Malaysia \\ Email: harwati@ukm.edu.my
}

How to cite this paper: Sam, I., \& Hashim, H. (2022). Pupils' Perceptions on the Adoption and Use of Toontastic 3D, a Digital Storytelling Application for Learning Speaking Skills. Creative Education, 13, 565-582. https://doi.org/10.4236/ce.2022.132034

Received: January 12, 2022

Accepted: February 15, 2022

Published: February 18, 2022

Copyright (๑) 2022 by author(s) and Scientific Research Publishing Inc. This work is licensed under the Creative Commons Attribution International License (CC BY 4.0).

http://creativecommons.org/licenses/by/4.0/ (c) (i) Open Access

\begin{abstract}
English is an important language for all kinds of professional and personal goals. However, learning English as a second language is often difficult as learners are learning in a language which is not their mother tongue. Speaking skills have always played a pivotal role in second language learning as they are essential in job employments. However, there have always been concerned with learners speaking ability in Malaysia. Therefore, with the advent of Information Communication Technology (ICT), researches have shown that Toontastic 3D, a Digital Storytelling Application could be used as a tool to improve speaking skills. Thus, this study explored pupils' perceptions on the adoption of Toontastic 3D in terms of its usefulness, ease of use and pupils' attitudes. 11 Year 5 pupils from a rural school in Melaka were selected through purposive sampling for this qualitative study and pupils' reflective journals and responses from semi-structured interviews were collected. This data was then analyzed using thematic analysis. Findings from the study revealed that most pupils perceived the adoption of Toontastic 3D in speaking activities positively such as Toontastic 3D as a useful tool to enhance speaking skills as well as for the pedagogical process. It was also observed that Toontastic 3D is also a user-friendly tool that enables pupils to access it easily. Therefore, it is hoped that Toontastic 3D can be an option for educators to utilize it as an assessment or a pedagogical tool for speaking skills especially in this digital era.
\end{abstract}

\section{Keywords}

Elementary, Perceptions, Toontastic 3D, Digital Storytelling Application, Speaking Skills 


\section{Introduction}

English is the most common second language in the world as it serves significant roles such as the international language, language of academia, tourism, international businesses and media (Ilyosovna, 2020). However, learning English as a second language is always challenging, because learners are learning a second language which is not their mother tongue. In learning English as a second language, speaking skills play a pivotal role and it is the most significant skill of the four language skills, because speaking includes all other skills of knowing the language and serves as a crucial means for communication that will eventually aid in securing a job during an interview or for further career development (Leong \& Seyedeh, 2017; Rao, 2019). However, speaking skills have always been undervalued for various reasons, including in Malaysia where it is deemed to be less important since it is not assessed in the national examination (Yahya, 2019). The lack of emphasis on the importance of speaking English would have resulted in their poor English communication skills that further led to issues such as unemployment among the graduates (Nesaratnam, 2020). According to the Economic Planning Unit (EPU), around 60,000 graduates in Malaysia are unemployed due to a lack of experience and inadequate English communication abilities (Hassan, 2018). It was also revealed that many English as Second Language (ESL) learners found it difficult to speak English due to various factors such as psychological factors, influences from teachers and peers, the management system and lack of vocabulary to express themselves in the language (Leong \& Seyedeh, 2017; Rusli, Md. Yunus, \& Hashim, 2018; Paneerselvam \& Mohammad, 2019; Nadesan \& Shah, 2020).

As there is awareness on the importance of speaking skills, diverse approaches varying from conducting communicative and collaborative activities such as debate and role play, watching English movies and listening to English songs, as well as gamification methods have been studied and suggested in curbing English as second language learners' weak mastery of speaking skills (Al-Rahmi, Othman, \& Rusa, 2014; Rusli et al., 2018). Although these approaches were studied, learners still lack the ability to speak English proficiently (Hassan, 2018). Therefore, following the rapid growth and development of technology in recent years, many advocates of technology have also looked into the use of technology as well as their readiness in the teaching practices (Bahadorfar \& Omidvar, 2014; Avelino \& Ismail, 2021). Digital storytelling is one of the approaches and it transforms the conventional style of delivering a story into a modern style that combines photographs, animations, videos, background music or sounds, text, and often a narrative voice with the use of technology (Frazel, 2010; Robin, 2016). Studies conducted in different areas such as Taiwan, Indonesia and Saudi Arabia have shown that digital storytelling has the potential to improve speaking skills because of the various interactive features such as animations, voice over and background music (Eissa, 2019; Kallinikou \& Nicolaidou, 2019; Yang, Chen, \& Hung, 2020). In Malaysia context, especially in the rural settings, this may be 
different, therefore it is important to explore elementary pupils' perceptions on the use of Toontastic 3D, a digital storytelling application for speaking skills. In addition, with the newly assessment reformation in Malaysia where the national examination that very much focused on writing skills in primary level is abolished and School Based Assessment (SBA) that assess all four skills is empowered, the need of uplifting speaking skills among ESL pupils in primary schools is inevitable (Ibrahim, 2021). Hence, it is important to explore the use of Toontastic 3D, a digital storytelling application for learning English speaking skills from the perspective of the pupils. Thus, the present study answered the following research questions:

1) What are the Year 5 pupils' perceptions on the usefulness of Toontastic 3D for speaking skills?

2) What are the Year 5 pupils' perceptions on the ease of use of Toontastic 3D for speaking skills?

3) What are the Year 5 pupils' attitudes in using Toontastic 3D for speaking skills?

\section{Literature Review}

\subsection{The Output Hypothesis in Second Language Acquisition}

Learning a second language is often seen challenging as it not the language of learners' mother tongue. Producing the target language or output has long been considered a crucial aspect in the teaching of second languages all around the world. Therefore, one of the second language acquisition theories that underpinned this study was Swain's Output Hypothesis. Swain's asserted that Output Hypothesis was the act of producing language (speaking and writing) constitutes, under certain circumstances as part of the process of second language learning (Swain, 1985). She argued that comprehensible output is valuable in improving both the accuracy and fluency of a second language because when learners face communication issues, they are forced to make their output more specific, clear, and suitable, according to the intelligible output construct, and this process is believed to enhance language learning (Swain, 1985).

One of the major functions of Output Hypothesis was the noticing function and this function would lead to the message being conveyed precisely, coherently and appropriately. For instance, a student will occasionally become aware of (i.e., notice) a linguistic difficulty (brought to his or her attention either by external feedback (e.g., clarification requests) or internal input) while creating the L2. Hence, he or she "pushed" to change his or her output after seeing a fault. As a result, the learner may be forced into a more syntactic processing mode than context comprehension mode. As a result, output may cause "noticing" to occur, activating mental processes that result in altered output (Swain, 2005). In lined with this, the process of attending classes and writing scripts during the activity would enable pupils to undergone this process as pupils would be given feedback and recheck on their grammatically errors before proceeding to the video mak- 
ing step.

\subsection{Technology Acceptance Model (TAM)}

Every day, educators are getting access to some new technologies and the integration of technology into education is emerging rapidly. Therefore, there is an increasing need to also understand why technology is embraced or rejected. In line with this, the Technology Acceptance Model (TAM) developed by Fred Davis in 1986 is the underlying theoretical framework for this present study in which attempts to explain how and why people implement new technologies. The TAM model is based on psychological theories and describes how computer user behaviour is influenced by beliefs, attitudes, intentions, and user behaviour. The aim of this model is to clarify the key factors that influence user acceptance of technology (Davis, 1989). The TAM model consisted of 5 constructs that show relational hypotheses that influence user acceptance of technology as shown in Figure 1.

These 5 constructs consisted of perceived usefulness (PU), perceived ease of use (PEU), attitude towards use (A), behavioural intention (BI) and actual use (AU). According to Davis (1989), PU indicated how one believes that using a specific technology will improve performances in the organizational context, PEU indicates how easily a person thinks a technology can be interpreted and utilized, A shows a person's positive or negative feelings about performing the target activity, $\mathrm{BI}$ is the behavior and desire to use the technology and this can be seen frequency of the technology used, attitudes and attention and AU indicates the level of the technology's actual use. Thus, this study adopted the TAM model to highlight how pupils perceived the adoption of Toontastic 3D, a digital storytelling application for speaking skills based on three key constructs from the model such as PU, PEU and A.

\subsection{Digital Storytelling and Its Benefits}

Teaching pedagogy has changed significantly over the years, where the traditional way of teaching has evolved into the modern way of teaching; conventional storytelling has transformed into digital storytelling. In general, digital storytelling is a fusion of recounting stories with a variety of multimedia, including graphics, audio, video, and Web publishing (Robin, 2008; 2016). The prominent pioneers of digital storytelling, Joe Lambert and the late Dane Atchley co-founded

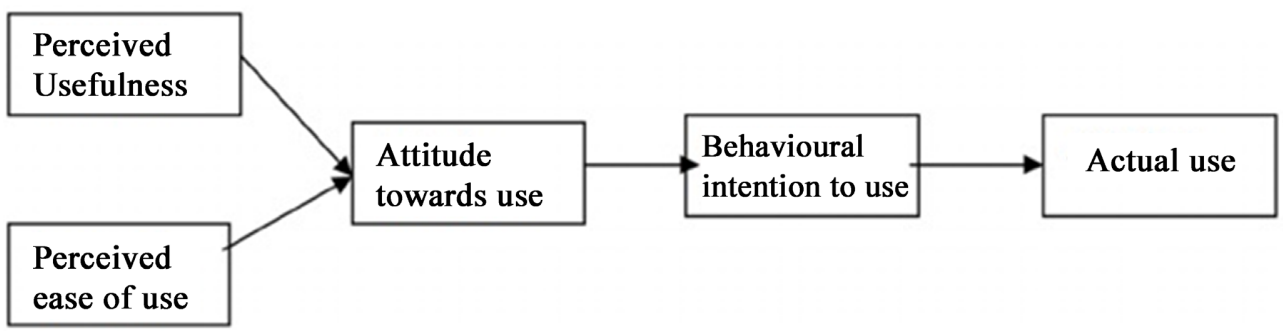

Figure 1. Technology acceptance model. 
the Centre of Digital Storytelling (CDS) in the late 1980s and supported the digital storytelling movement (CDS, 2005). Since then, digital storytelling is becoming more established and many educators at all levels have utilized digital storytelling in a huge number of ways from creating new materials in order to attract learners' interests to facilitating learners' discussion during the teaching process (Kent, 2010; Robin, 2016).

Likewise, digital storytelling can be a robust educational tool for learners of all ages especially when they are assigned to create the stories, either individually or in groups. It is proven to be an effective educational tool to enhance learners' language skills, for instance, reading skills, writing skills, speaking skills and even vocabulary (Precintha Rubini et al., 2019; Eissa, 2019; Chiang, 2020). With regards to speaking skills, studies show that digital storytelling can be useful in improving one's speaking skills and this is attributed to the fact that the participants are able to work at their own pace and in small groups, hence are able to be more confident in speaking the language besides being able to practice speaking the language since they can re-record their stories for multiple times in order to submit the best version of their digital stories (Kallinikou \& Nicolaidou, 2019; Eissa, 2019). Besides, Eissa (2019) had also revealed in her study that $90 \%$ of the research participants agreed that the use of digital storytelling for speaking activities was able to enhance one's vocabulary acquisition as this strategy allowed them to choose appropriate vocabulary and structure. A case study conducted by Rosli (2019) further support this claim as they students expressed that they were able to learn new words while coming up with the scripts.

Other than that, digital storytelling also contributed largely in the pedagogy process as it serves as a catalyst and motivator in promoting active participations among learners. A qualitative study conducted by Amelia and Abidin (2018) to investigate the effects of using digital storytelling application in English language learning had revealed that due to the great interactivity of the multimedia features embedded into the application, learners were driven to learn. The key features that had motivated them to learn English using digital storytelling application were the animations, voiceover narration, hyperlinked vocabularies, and multimodal glosses. Eissa (2019) shared similar findings but added that about 97.5\% participants in her study agreed that the use of digital storytelling was able to eliminate fear in them to speak English in groups or with people, thus motivate them to participate the lesson actively. Aside from the interesting features and psychological factors that could motivate learners to learn through digital storytelling applications, the application's ease of use could also contribute to motivating students to learn actively, as simple and user-friendly tools can increase learners' agency, whereas complicated tools limit it (Merjovaara, Nousiainen, Turja, \& Isotalo, 2020).

In addition, the implementation of digital storytelling had also contributed to the positive attitudes among the learners, such as being happy, showing interest and realizing the importance of speaking skills (Kallinikou \& Nicolaidou, 2019; 
Chiang, 2020). According to Kallinikou and Nicolaidou (2019), the utilization of digital storytelling application enables pupils to personalize their learning experiences and work at their own pace, thus attributing to the positive learning attitudes among them. Moreover, Chiang (2020) highlighted that learners found using digital storytelling application made lessons more exciting, less inhibiting and enjoyable, thus contributing to learners showing much interest and preferring digital storytelling integrated lessons over conventional lessons.

However, with the huge range of digital storytelling applications available for the learners, it is important to look into a specific type of digital storytelling application and how its features will affect the learners' perceptions. Many of the above studies had been conducted in areas such as Taiwan, Indonesia and Saudi Arabia, therefore conducting this present study in a rural setting in Malaysia, to better understand elementary pupils' perceptions on the adoption of Toontastic $3 \mathrm{D}$, a digital storytelling application for speaking skills, makes this study important for local context.

\subsection{Toontastic 3D}

Toontastic 3D is a digital storytelling application for iOS and Android that is inspired by puppetry, theater, and animation (Vanderborght, 2017). This application, created in association with Google, offers various 3D scenes, characters and drawing tools that empower kids to select, animate, narrate, and record their own stories on their tablet, phone or Chromebook. It is also free, easily exportable and can be used offline.

Toontastic 3D offers 3 story layouts for creators to select, namely short story, classic story, and science report. The short story layout which is used in this study comes in three parts such as beginning where creators introduce characters and plots, followed by middle where conflicts arise and end where it serves as the epilogue. For each plot point, creators can select the available settings and 3D characters or draw their own characters for their stories. To begin with, creators tap the recording buttons, move the characters and props around, investigate the set, and narrate the story. Every scene can record as long as 60 seconds of voice narration and animation. The last stage is to include the available soundtracks as background music. Once completed, recorded stories from each plot point will be combined together into a solitary video as a whole. Creators then can access the videos from their gallery or camera roll.

According to Vanderborght (2017), one of the greatest advantages of this application is that students are the directors and have the freedom to let their creativity shines through this user-friendly storytelling application. The features of dragging and moving characters around while narrating a story have made it easier for the students to create their stories. Thus, it enables them to learn the basics of storytelling while easily creating fun animated stories. Other than that, a study conducted by Salgado and Doria (2019) has claimed that Toontastic 3D encourages students to speak independently especially when the application it- 
self has the representation of different stages for the stories, so it serves as a great scaffolding process for students' learning. The process of creating the stories using Toontastic 3D also aids in stimulating pupils' cognitive development and the interesting cartoon characters and animation features have motivated students to learn during the process (Regim, Howell, Robert, \& Melor, 2018). Therefore, Toontastic 3D can be a great technology tool to be ventured on in teaching and learning.

\section{Methodology}

\subsection{Research Design}

This study employed a qualitative approach where data collected were based on pupils' reflective journals and responses during the semi-structured interview. According to Duff (2014), a qualitative study is exploratory in nature and appropriate when the purpose is to understand people's experiences and growth paths inside a specific educational context. In this case, it attempted to gain insights from the pupils on the use of Toontastic 3D, a digital storytelling application for speaking activities in the classroom.

\subsection{Research Participants and Setting}

This study involved a Chinese primary school (SJKC), located in a rural area at Alor Gajah, Melaka. Due to the geographical location of this school, most pupils had limited exposure and opportunity to learn English outside of the classroom, hence they often underperform in English subject. Thus, this school was selected as the research setting to provide pupils the opportunity to learn English and better understand their perceptions on the use of Toontastic 3D. 11 Year $5 \mathrm{pu}$ pils were employed as the research participants for this study through purposive sampling and all 11 pupils in this study were selected with the criteria of scoring at or lower than performance level 3 in their first CEFR aligned School-Based Oral Assessment which was taken in June. This indicated that they were relatively weak and underperformed in the English subject. Although these pupils own technologies such as smartphones or tablets, yet these gadgets were not used for learning purposes but rather for entertainment purposes. Despite the small sample size in this study which prevents generalization, the data can be applied to other similar situations.

\subsection{Research Procedures}

This study was conducted for 6 weeks via online and Figure 2 displayed the procedures and phases undertaken. This study was divided into three phases which were the introduction phase, instructional phase and evaluation phase.

During the introduction phase, pupils were introduced and exposed to Toontastic 3D application. They were given a week time to venture on the application. The next 4 weeks were the instructional phase where pupils were given lessons about two topics taken from their English Plus Textbook and were required to 


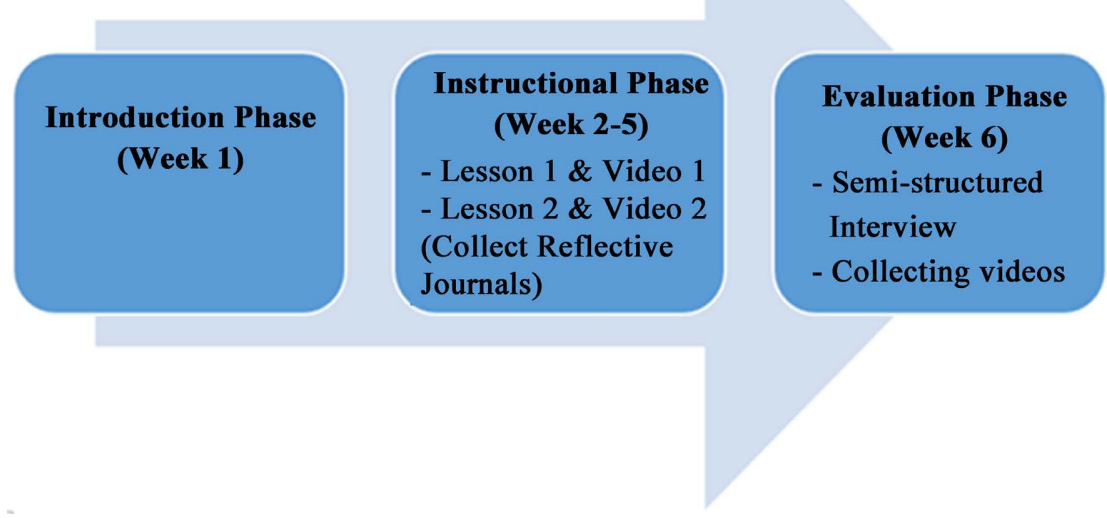

Figure 2. Research procedures.

create 2 digital stories based on the 4 steps of the digital storytelling process below adapted from Morra's (2013) 8 Steps of Digital Storytelling Framework.

1) Step One: Research, Explore and Learn

- Pupils were given a topic for creating the story. Then, they explored and learned about the topic as well as certain language focuses through lessons given by the teacher.

2) Step Two: Writing the Script

- In this stage, pupils wrote the script for their story based on the topic given. They could write in pairs or individually. Feedbacks were given by the teacher so that pupils could work on editing and revising their script constantly to produce the best script. Pupils were also required to memorize the script rather than read the script while recording the story.

3) Step Three: Creating the digital story

- Pupils then used Toontastic 3D, to create their animated digital stories. They could choose settings and characters provided in the application, then narrate, animate and record their story in video form based on the script.

4) Step Four: Share and Feedback

- Pupils submitted their digital stories in video form to their teacher. The teacher shared pupils' final products during classes and gave feedback to ensure better productions for the next round. Pupils' reflective journals were also collected in the instructional phase after each digital storytelling-making session. The last phase was the evaluation phase which involved collecting their videos and conducting telephone interviews.

\subsection{Data Collection Method and Analysis}

This study employed a qualitative data gathering method where the data consisted of pupils' reflective journals and audio recorded interviews with the pupils. The reflective journals were written by pupils after each digital storytel- 
ling-making session and depicted their feelings as well as what they like or dislike about the use of Toontastic 3D. In addition, a semi-structured interview with each pupil through telephone call was conducted by the end of the study to gather in-depth information of pupils' perceptions on the use of Toontastic 3D for speaking activities. The interview consisted of eight semi-structured items which were adapted from a previous study (Alexandrakis, Chorianopoulos, \& Tselios, 2020) and reconstructed around themes such as perceived usefulness, ease of use and attitude. Face and content validity were conducted with an expert in the ESL field. The process involved reviewing the research questions, commenting on the relevance of the questions as well as the suitability of the language used (Creswell \& Clark, 2011). The initial 6 items were then revised and amended into 8 items according to the feedback given by the expert.

Upon collecting all the data, the data were transcribed and analyzed using thematic analysis by Braun and Clarke (2006). Braun and Clarke's thematic analysis framework consisted of six phases beginning with becoming familiar with the text, then coding the content in an organized way, followed by clustering the text units or codes into themes, reviewing the themes and correlating with the research questions, then refining the themes by naming each theme informatively and lastly weaving the data extracts and analytic narrative together, as well as contextualizing the research in light of existing literature.

\section{Findings and Discussion}

In addressing the research questions of this study as stated in Table 1, pupils were interviewed (INTVW) and their reflective journals (RJ) were collected for thematic analysis purposes. 3 themes were derived to answer the first research question on the perceived usefulness of Toontastic 3D for speaking skills, followed by one theme derived to answer the second research question about the ease of use of Toontastic 3D and one theme was found in addressing the third research question on the attitudes of the pupils. For a better overview, the 5 emerged themes with their respective categories and codes in answering all three research questions are illustrated in Table 1.

\subsection{Useful Tool to Learn Speaking English Effectively}

In answering the first research question, the first theme that derived is Toontastic 3D is a useful tool to learn speaking English effectively. This meant that with the use of Toontastic 3D, pupils were able to acquire the language skill more successfully especially when learning a second language is not easy. The foremost reason identified by the pupils was because the utilization of this digital storytelling application enabled them to practice the language at most, followed by the recording and re-recording processes that aided them in learning to speak English effectively. Below are some of the excerpts of pupils' reflective journals as well as interview responses that indicated Toontastic $3 \mathrm{D}$ enabled them to practice speaking English more often than they would. 
Table 1. Emerged codes, categories and themes.

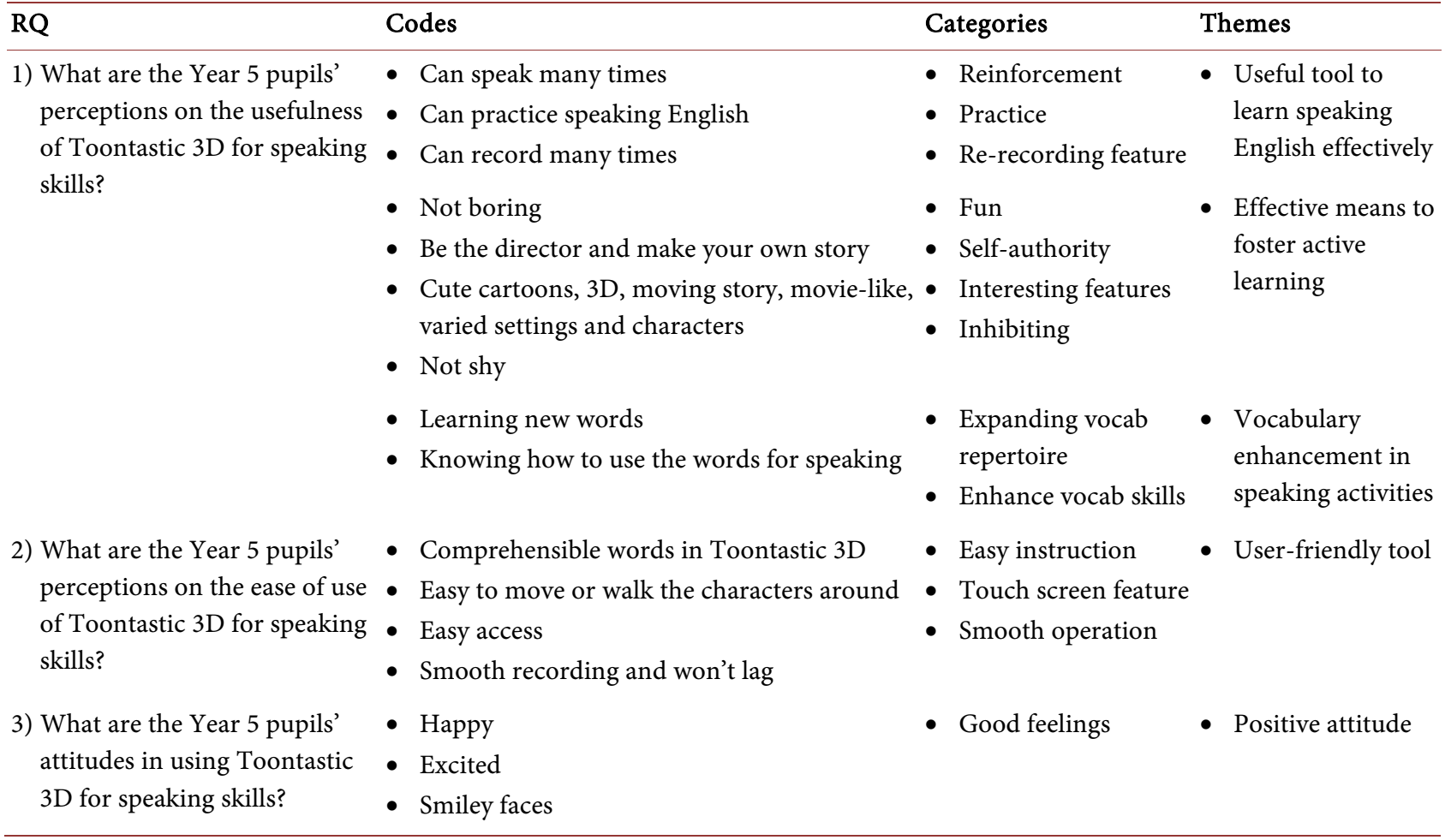

I like it because I can practice on how to ask direction using English. (P10, RJ)

Yes, useful because we can practice speaking English using it. (P4, INTVW)

Yes, useful. We can speak more English to make the stories. (P5, INTVW)

We can record many times and speak many times. (P6, INTVW)

Yes, when people speak English with us, we know how to reply back. (P9, INTVW)

Yes, because we can practice and use our voice to record the stories. (P11, INTVW)

This could be explained by the fundamental role of Swain's Output Hypothesis (1985) in L2 learning where learners are "pushed" to process language more actively and profoundly, hence mediating L2 learning. The process of writing the scripts by applying some key phrases or sentences learned during the lessons as well as the re-recording process to get the best video had eventually "pushed" them to learn and acquire the language explicitly, focusing not only on the comprehension but also emphasizing the importance of some useful language structures or words, thus aiding them to learn speaking English effectively. This was also supported by previous studies that acknowledged digital storytelling enabled pupils to practice and enhance speaking abilities (Kallinikou \& Nicolaidou, 2019; Eissa, 2019).

\subsection{Effective Mean to Foster Active Learning}

Apart from being useful to learn speaking English effectively, Toontastic 3D was 
also found to be an effective mean to foster active learning among learners, in which answered the first research question on its perceived usefulness. This meant that rather than passively receiving information from the teacher, Toontastic 3D was useful in making them actively involved in the learning process. Hence, Toontastic 3D was purported to be beneficial not only for the language skill but also for the pedagogical process as pupils claimed that the interesting features in Toontastic 3D had attracted their interests into the learning followed by some psychological factors that encouraged their participation in the project. All of the pupils had eventually pinpointed certain features in Toontastic 3D such as the varied choices of cute $3 \mathrm{D}$ characters and unique settings, the moving animations, the drawing feature and movie-like design had made the storytelling process more fun and interesting, thus attracting their interest in using it to create movie-like stories in English during the lesson. This was evidenced in some of their reflective journals and interview as shown below.

I like using Toontastic 3D for speaking activities because the characters are very cute and I also can make a cartoon movie. (P7, RJ)

There are also many special places and special characters which is cool. (P8, $\mathrm{RJ})$

I like Toontastic 3D because the cartoons can fly and move around. It's very interesting. (P9, RJ)

Toontastic 3D is fun for lesson. I can be the director and make my own stories. (P4, INTVW)

I felt happy and excited about it. Because there are cartoons and they are 3D. (P6, INTVW)

Results from various past studies further corroborated findings above as they had proven that digital storytelling was able to motivate and foster pupils' learning due to the various interactive features (Amelia \& Abidin, 2018; Regim et al., 2018; Chiang, 2020).

Interestingly, 3 pupils had highlighted the psychological aspects in which they claimed to feel less inhibited and intimated to speak English when using Toontastic 3D because they were able to record the stories and re-record them if mistakes were made. Hence, it would eventually boost up their confidence and subsequently encourage them to participate in the lesson actively. This could be seen in their responses in the interview as well as their reflective journals below.

I like Toontastic 3D because I am not shy when I use Toontastic to make videos. (P3, RJ)

I am not scared when make and tell story from Toontastic 3D. (P5, RJ)

I like Toontastic 3D for speaking activity because I'm not shy when I record video and I can record many times to tell stories. (P11, RJ)

In parallel with these findings, Eissa (2019) also indicated that digital storytelling applications enabled learners to overcome all psychological difficulties such as shyness, nervousness and anxiety that previously made them incapable of 
speaking English effectively. Therefore, Toontastic 3D could act as a catalyst in promoting active learning.

\subsection{Vocabulary Enhancement in Speaking Activities}

Upon reflecting on their experiences in using Toontastic 3D throughout the whole process beginning from exploring, writing the scripts, creating the videos till sharing and giving feedbacks, 5 pupils had expressed that Toontastic 3D offered them the learning experiences of improving their vocabulary, which was an integrated part of the speaking components. This had also addressed the first research question as Toontastic 3D was perceived useful in terms of enhancing vocabulary. One of the plausible explanations for this was during the process of writing the scripts and producing the digital stories, pupils would explore and search for the appropriate words to be used in their story based on the topic given such as "Making Plans" and "About Direction". Hence, it offered them the opportunities to explore and expand their vocabulary repertoire besides finding out what words or key phrases were suitable to be used in that specific contexts. Below were some of the feedbacks given by the pupils that explained that use of Toontastic in enhancing one's vocabulary repertoire and skills.

I can learn new words. (P1, INTVW)

There are some English words that I don't know how to read and say, but after recording for few times, I know how to say it. (P3, INTVW)

Err...I think vocab because I know what words to use in the stories. (P7, INTVW)

I think vocab. I know how to use the words when making stories. (P9, INTVW)

We can learn a lot of words and do storytelling. (P11, INTVW)

This was congruent with results from some of the past studies where they revealed that digital storytelling enabled learners to choose the proper vocabulary and to use the correct sentence structure (Eissa, 2019; Rosli, 2019). According to a review by Raw and Ismail (2021), various researches have shown that digital tools can help people master words more effectively because they provide a variety of great psychological and cognitive conditions that affect short and long-term memory.

\subsection{User-Friendly Tool}

Besides being claimed to be useful, Toontastic 3D was also perceived to be a user-friendly digital storytelling application for learning in the classroom. This had answered the second research question pertaining to its ease of use. User-friendly in this context was meant by Toontastic 3D was an easy to use digital storytelling application as 8 pupils stated that it is "easy" to use the application and only 3 stated it's "fairly easy" to use the application. 5 pupils pointed out the smooth operation of this application such as the easy recording process with only one click, the re-recording feature and not lagging property had made this applica- 
tion accessible for all. Nonetheless, the simple and easily comprehend English instruction as mentioned by one of the pupils as well as the touch screen feature highlighted by another pupil had greatly contributed to the user-friendliness of this application. Unlike other digital storytelling applications such as Storybird or Story Creators which focus more on $2 \mathrm{D}$ images, Toontastic 3D offered pupils to create animated stories with $3 \mathrm{D}$ cartoon characters by just dragging and moving the characters through its touch screen feature. Hence, making it easy to access and operate by users. Following were some of the evidence from pupils' feedback regarding the user-friendliness of this application.

Because it's not difficult and the words in Toontastic 3D is easy to understand. (P3, INTVW)

Easy to use. Because the recording is very smooth and won't lag. (P6, INTVW)

It is very easy to use. Because there are many characters for us to choose.

There are also many settings for us to choose already. (P7, INTVW)

Easy to use. Because it's touch screen. (P8, INTVW)

Easy as it is easy for us to move or walk the characters around. (P9, INTVW)

It is because it's very easy to record with just one click and can store it. (P10, INTVW)

According to Vanderborght (2017), the features of dragging and moving characters around while narrating a story had made it easier for the students to create their stories. Thus, Toontastic 3D enabled them to learn the basics of storytelling effectively while easily creating fun animated stories. A previous study from Merjovaara et al. (2020) had also indicated that simple and user-friendly tools could improve learners' agency whereas complicated tools limit it. Therefore, it was important for educators to carefully evaluate the affordance and accessibility of an application before selecting the suitable digital storytelling application within the myriad of choices.

\subsection{Positive Attitudes}

In addressing the third research question which focused on pupils' attitudes towards the implementation of Toontastic $3 \mathrm{D}$, the findings had revealed that pupils manifested positive attitudes after the implementation of Toontastic 3D. 10 pupils had drawn smiley faces in some of their reflective journals (as shown in Figure 3) to express their happy and excited feelings upon completion of the video. Only one of them had drawn angry faces to show their frustration when using the application due to some limited animations offered by the application such as the limited animations offered. Pupils also documented that the fun elements or features such as animated 3D cartoons, voice-over narration, recording features and background music had made speaking activity less mundane and more likable for the children. Pupils liking it and feeling happy about it was mostly contributed by the positive feedback given in regards to the usefulness 


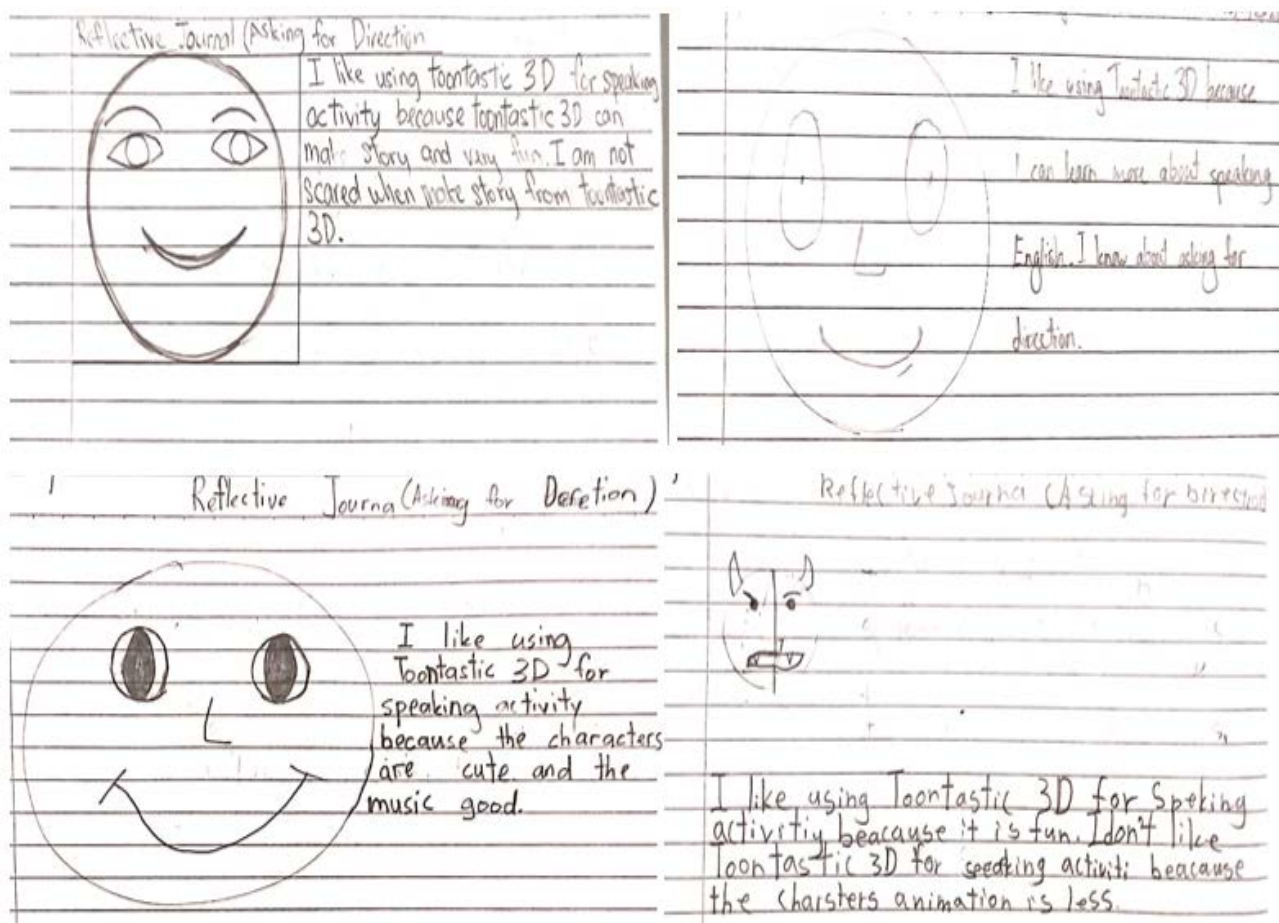

Figure 3. Pupils' reflective journals on feelings.

and ease of use of the application which was in line with the fundamental concept of Technology Acceptance Model by Fred Davis (1989) that explained how and why people implement new technologies by identifying the key constructs or factors. In this case, Toontastic 3D was perceived useful by pupils in terms of improving speaking skills, vocabulary and active learning as well as an easy to use tool, hence this explained the attendance of positive attitudes among the pupils in this study.

Besides drawing happy and smiley emoticons, all pupils had also given positive feedbacks in relation to their feelings after utilizing Toontastic 3D in speaking activities such as feeling happy and good as shown below.

I felt happy. When we play it, we can learn English and it's not boring. (P3, INTVW)

I felt happy and excited about it. (P4, INTVW)

I felt good because it's very fun and the cartoons are cute. (P7, INTVW)

It is very easy to use to do a video. I feel happy to use it. (P8, INTVW)

I feel happy because the characters can fly and walk around. (P9, INTVW)

I felt great because it is very fun and interesting. (P11, INTVW)

Previous studies had also affirmed that positive attitudes such as excitement, happy and enthusiastic were being portrayed by research participants after the implementation of digital storytelling (Kallinikou \& Nicolaidou, 2019; Chiang, 2020). However, this had contradicted the study from Hava (2019) as it was found that there was no change in students' attitudes towards the liking of English after the implementation of digital storytelling. The researcher had ex- 
plained that the plausible reason for this was because a long period of time and repetition of new experiences were needed in order to change students' attitudes. In line with this, this study had been conducted for about 6 weeks with pupils creating 2 videos based on 2 given topics. Hence, the time frame was considerably long enough to see changes in attitudes.

\section{Conclusion}

The overall findings from this study suggested that Toontastic 3D could be a practical and empowering pedagogical supplement to an existing ESL speaking course. Besides proving its effectiveness in aiding pupils to speak English effectively as well as enhancing one's vocabulary skills, it had also contributed to the pedagogical process by encouraging active participation among learners. Furthermore, this study had also pointed out the accessibility and affordance of the application. Its user-friendly properties such as touch screen feature, offline agent and smooth operations had also led pupils' to accept and portray positive attitudes towards speaking activities.

In line with the latest assessment reform in Malaysia reported in Berita Harian, where the standardized elementary examination across nation (UPSR) was no longer being implemented but School-Based Assessment was being emphasized strongly and speaking skills was being assessed explicitly, the need to provide an assessment tool for teachers in primary schools was inevitable (Ibrahim, 2021). Therefore, it was believed that with the use of Toontastic 3D, teachers were able to assess pupils' speaking abilities based on the videos created. Besides, it was also hoped this study could shed some light on the organizers or stakeholders in diversifying the choices of applications that could be used for their recent district or state level digital storytelling competitions, which was a relatively new event under the student development sector in the Ministry of Education in Malaysia.

However, this paper was not without limitations. Self-report measures of Toontastic 3D for speaking skills were collected using pupils' reflective journals and interview to gather data about the participant's experiences and perspectives. This indicated that the results were dependent on the students' subjective evaluations of their abilities. Furthermore, just one researcher conducted the qualitative data analysis, and no reliability coefficient was calculated. As a result, the generalization of the findings was limited. Future research could make use of more data sets such as observation and documents collected from various parties such as teachers, school admins and pupils to ensure the reliability of the results and avoid students' subjective evaluations of the intervention.

\section{Acknowledgements}

The authors would like to acknowledge Ministry of Higher Education Malaysia (MOHE) under the Fundamental Research Grant Scheme (FRGS) with project code no. FRGS/1/2019/SS09/UKM/02/2 for the support of this research and Un- 
iversiti Kebangsaan Malaysia under research grant no. GG-2021-003.

\section{Conflicts of Interest}

The authors declare no conflicts of interest regarding the publication of this paper.

\section{References}

Alexandrakis, D., Chorianopoulos, K., \& Tselios, N. (2020). Older Adults and Web 2.0 Storytelling Technologies: Probing the Technology Acceptance Model through an Age-Related Perspective. International Journal of Human-Computer Interaction, 36, 1623-1635. https://doi.org/10.1080/10447318.2020.1768673

Al-Rahmi, W. M., Othman, M. S., \& Musa, M. A. (2014). The Improvement of Students' Academic Performance by Using Social Media through Collaborative Learning in Malaysian Higher Education. Asian Social Science, 10, 210-221.

Amelia, L. C. H., \& Abidin, M. J. Z. (2018). Young ESL Learners' Perception on the Effects of Using Digital Storytelling Application in English Language Learning. Pertanika Journal of Social Sciences \& Humanities, 26, 179-198. http://www.pertanika.upm.edu.my/resources/files/Pertanika\%20PAPERS/JSSH\%20Vol \%2026\%20(T)\%20Dec.\%202018/13\%20JSSH-2615-2017.pdf

Avelino, N. M., \& Ismail, H. H. (2021). Assessing ESL Teachers' Knowledge and Readiness in Integrating 4IR into Teaching Practices: A Concept Paper. Creative Education, 12, 2038-2055. https://doi.org/10.4236/ce.2021.129156

Bahadorfar, M., \& Omidvar, R. (2014). Technology in Teaching Speaking Skill. Acme International Journal of Multidisciplinary Research, 2, 9-13.

Braun, V., \& Clarke, V. (2006). Using Thematic Analysis in Psychology. Qualitative Research in Psychology, 3, 77-101. https://doi.org/10.1191/1478088706qp063oa

Center of Digital Storytelling (CDS) (2005). Educational Uses of a Digital Storytelling. https://digitalstorytelling.coe.uh.edu/page.cfm? $\mathrm{id}=27 \& \mathrm{cid}=27 \&$ sublinkid=29

Chiang, M. H. (2020). Exploring the Effects of Digital Storytelling: A Case Study of Adult L2 Writers in Taiwan. IAFOR Journal of Education, 8, 65-82. https://eric.ed.gov/?id=EJ1245831

Creswell, J., \& Clark, V. (2011). Designing and Conducting Mixed Method Research. Los Angeles: SAGE Publications.

Davis, F. D. (1989). Perceived Usefulness, Perceived Ease of Use, and User Acceptance of Information Technology. MIS Quarterly, 13, 319-340. https://doi.org/10.2307/249008

Duff, P. A. (2014). Case Study Research on Language Learning and Use. Annual Review of Applied Linguistics, 34, 233-255. https://doi.org/10.1017/S0267190514000051

Eissa, H. M. S. (2019). Pedagogic Effectiveness of Digital Storytelling in Improving Speaking Skills of Saudi EFL Learners. Arab World English Journal, 10, 127-138.

Frazel, M. (2010). Digital Storytelling Guide for Educators. Washington DC: International Society for Technology in Education.

Hassan, A. (2018). Internship Framework Guidelines for Malaysian Public Higher Education Institutes. Journal of Science, Technology and Innovation Policy, 4, 20-28.

Hava, K. (2019). Exploring the Role of Digital Storytelling in Student Motivation and Satisfaction in EFL Education. Computer Assisted Language Learning, 34, 958-978. https://doi.org/10.1080/09588221.2019.1650071 
Ibrahim, M. I. (2021). UPSR Mansuh, PT3 Dibatalkan. Berita Harian.

https://www.bharian.com.my/berita/nasional/2021/04/811621/upsr-mansuh-pt3-dibata $\underline{\text { lkan }}$

Ilyosovna, N. A. (2020). The Importance of English Language. International Journal on Orange Technologies, 2, 22-24.

Kallinikou, E., \& Nicolaidou, I. (2019). Digital Storytelling to Enhance Adults' Speaking Skills in Learning Foreign Languages: A Case Study. Multimodal Technologies and Interaction, 3, Article No. 59. https://doi.org/10.3390/mti3030059

Kent, D. B. (2010). Digital Storytelling: From Theory to Practice. In TESOL Arabia 16th International Conference: Transformations in TESOL (pp. 11-13). Pedagogy Press. https://ww4.ticaret.edu.tr/mis/wp-content/uploads/sites/102/2020/03/dig story ders.p df

Leong, L. M., \& Ahmadi, S. M. (2017). An Analysis of Factors Influencing Learners' English Speaking Skill. International Journal of Research in English Education, 2, 34-41. https://doi.org/10.18869/acadpub.ijree.2.1.34

Merjovaara, O., Nousiainen, T., Turja, L., \& Isotalo, S. (2020). Digital Stories with Children: Examining Digital Storytelling as a Pedagogical Process in ECEC. Journal of Early Childhood Education Research, 9, 99-123. http://urn.fi/URN:NBN:fi:jyu-202002242155

Morra, S. (2013). 8 Steps to Great Digital Storytelling-Transform Learning. https://samanthamorra.com/2013/06/05/edudemic-article-on-digital-storytelling/

Nadesan, N. K., \& Shah, P. M. (2020). Non-Linguistic Challenges Faced by Malaysian Students in Enhancing Speaking Skills. Creative Education, 11, 1988-2001. https://doi.org/10.4236/ce.2020.1110145

Nesaratnam, S. (2020). Enhancing English Proficiency and Communication Skills among Malaysian Graduates through Training and Coaching. International Journal of Learning and Development, 10, 1-21.

Paneerselvam, A., \& Mohamad, M. (2019). Learners' Challenges and English Educators' Approaches in Teaching Speaking Skills in an ESL Classroom: A Literature Review. Creative Education, 10, 3299-3305. https://doi.org/10.4236/ce.2019.1013253

Precintha Rubini, A., James, P. P., Yong, K. L., \& Yunus, M. M. (2019). Hear Me out! Digital Storytelling to Enhance Speaking Skills. International Journal of Academic Research in Business and Social Sciences, 9, 190-202.

Rao, P. S. (2019). The Importance of Speaking Skills in English Classrooms. Alford Council of International English \& Literature Journal (ACIELJ), 2, 6-18.

Raw, S. D. M., \& Ismail, H. H. (2021). Tracing Effectiveness and Challenges in Using Online Tools to Enhance Vocabulary Language Learning: A Review. International Journal of Academic Research in Progressive Education and Development, 10, 938-952.

Regim, C. Y., Howell, S. E., Robert Ayin, I., \& Yunus, M. M. (2018). Toontastic 3D for Writing. In N. F. Z. Abedin (Ed.), International Invention \& Innovative Competition (InIIC) (pp. 182-185). MNNF Publisher.

Robin, B. R. (2008). Digital Storytelling: A Powerful Technology Tool for the 21st Century Classroom. Theory into Practice, 47, 220-228.

https://doi.org/10.1080/00405840802153916

Robin, B. R. (2016). The Power of Digital Storytelling to Support Teaching and Learning. Digital Education Review, No. 30, 17-29.

Rosli, R. M. (2019). Emphasizing the Importance of Digital Storytelling in Rural Schools in Malaysia. Journal of Advanced Research in Social Sciences and Humanities, 4, 40-50.

Rusli, R., Yunus, M., \& Hashim, H. (2018). Low Speaking Proficiency among the Malay- 
sian Undergraduates: Why and How. Persidangan Antarabangsa Sains Sosial dan Kemanusiaan, 3, 678-689.

http://conference.kuis.edu.my/pasak3/images/eprosiding1/PASAK3 2220.pdf

Salgado, M., \& Doria, C. (2019). Encouraging 9th Graders to Tell Anecdotes through R21 Using Toontastic 3D. Degree's thesis, University of Cordoba]. University of Cordoba Research Repository.

https://repositorio.unicordoba.edu.co/handle/ucordoba/2462? show=full

Swain, M. (1985). Communicative Competency: Some Roles of Comprehensible Input and Comprehensible Output in Its Development. In S. Gass, \& C. Madden (Eds.), Input in Second Language Acquisition (pp. 235-253). Rowley: Newbury House.

Swain, M. (2005). The Output Hypothesis: Theory and Research (pp. 495-508). Routledge. https://doi.org/10.4324/9781410612700-38

Vanderborght, M. (2017). Toontastic 3D Review for Teachers. Common Sense Education. https://www.commonsense.org/education/app/toontastic-3d

Yahya, M. Y. (2019). Improving Speaking Performance and L2 Motivation through Task-Based Language Teaching on Malaysian Undergraduate Students. University of Reading.

Yang, Y. T. C., Chen, Y. C., \& Hung, H. T. (2020). Digital Storytelling as an Interdisciplinary Project to Improve Students' English Speaking and Creative Thinking. Computer Assisted Language Learning, 33, 1-23. https://doi.org/10.1080/09588221.2020.1750431 